\title{
Book review: Teaching for quality learning at university ( $4^{\text {th }}$ edition) Biggs, J. \& Tang, C. (2011), Open University Press
}

\section{Christina (CJ) Davison}

Zayed University, UAE

In Teaching for quality learning at university, the authors explore the idea that teaching quality can be improved by aligning learning outcomes, teaching and learning activities and assessment tasks through a framework called constructive alignment. The main argument is that to improve the quality of teaching and learning, the focus needs to be placed on what students do in and out of the classroom, rather than on what teachers do. Constructive alignment is the deceptively simple concept that includes setting a desired learning outcome, designing teaching and learning activities that support student achievement of that outcome, and then designing assessments that measure the achievement of the outcomes. The book is divided into three main sections: Part I sets the context, Part II focuses on the design of constructively aligned teaching, and Part III steps through some implementation examples.

Part I sets the context for the idea of constructive alignment. It traverses a wide number of issues that will be familiar to anyone with recent teaching experience in a university: diversity and changes in student populations, problems with student motivation and a preference for surface rather than deep approaches to learning. A helpful description of students is introduced and used throughout the book: Susan the 'academic' and Robert the 'non-academic'. Susan is a motivated and knowledgeable 'good' student, while Robert represents a student that wouldn't have traditionally been in university, is not quite sure why he is studying or what his goals are, and is passive and difficult to engage in class. This description is then used to reconsider teaching approaches to focus on encouraging the 'Roberts' to participate in the kinds of active learning behaviours and metacognitive processes that the 'Susans' seem to do independently without prompting. In this strategy, the focus is on the manner of learning rather than simply blaming weak students for not keeping up or being underprepared, or falling into the trap that the teacher needs to do more to try to entertain the class to keep the 'Roberts' interested.

The authors introduce a helpful characterization of a educational climate continuum between "Theory $X$ " and "Theory $Y$ ". In a "Theory $X$ " climate, students and faculty are not trusted and in a "Theory $Y$ " climate they are trusted. A "Theory $X^{\prime \prime}$ classroom focused on compliance may lead to students taking surface approaches to learning, while in a "Theory $Y$ " climate students are given the leeway to make some of their own learning-related choices, and presumably deeper approaches to learning. The reader is encouraged to consider what kind of classroom climate they want to foster, recognising that being too far to either side is chaotic.

Part I is rounded out by introducing the Structure of Observed Learning Outcomes (SOLO) taxonomy, and the main idea of the book: constructive alignment. The SOLO taxonomy is a Bloom's cognitive taxonomy-like hierarchy of levels of thinking but uniquely focuses on the building structural complexity of student's knowledge. The stages are somewhat academically named prestructural, unistructural, multistructural, relational and extended abstract. However, the taxonomy highlights the way that knowledge structures move hierarchically from being scattered unlinked ideas, to related ideas, through to being able to extend and generalise concepts to new situations. It is a useful framework for both designing learning outcomes and assessments from simple to more complex. 
Constructive alignment places the focus of teaching on what the learner is expected to both know and do, and away from what the teacher covers. It is concentrated equally on the content to be learned, and how, or to what level it is to be learned. For example, an intended learning outcome includes a verb like 'explain topic $X$ '. Constructive alignment would encourage a check that the teaching and learning activities planned would truly focus on having the students practice 'explaining' the topic. An example of misaligned teaching and learning activity might be, for example, students listening to a lecture and reading about the topic, which would not give them an opportunity to practice 'explaining'. Then an aligned assessment task would also focus on a student's ability to explain the topic. The idea is deceptively simple: step through the process of outlining what students are intended to learn, ensure that the teaching and learning activities give the students frequent and varied opportunities to practice enacting the intended learning outcome, and then confirm that the assessment measures the intended learning outcome.

Part II of the book examines in detail how to design a constructively aligned system of teaching and assessment. It covers both declarative and functional knowledge at the institutional, program and course level of outcomes. Declarative knowledge is understanding about things that have already been discovered, the factual, book-smart kind of information; functional knowledge is how we apply our declarative knowledge to make good decisions and solve problems. Each type of knowledge is given a full chapter to investigate teaching approaches to support learning, and another chapter on methods to assess it. The declarative knowledge section explains a variety of helpful ways to re-envision a lecture or tutorial as learning situations and make them more interactive. Functional knowledge outcomes, often favoured in graduate outcomes, are particularly difficult to teach in a traditional manner. Therefore a section introduces approaches like case-based learning, group work, reflective learning and problembased learning as ways to address this. There is an especially useful context-setting chapter that explains the shift from the measurement model of assessment, where student achievement is measured by how they compared to each other, to the standards-based model where students are graded against their attainment of a standard level of performance. Many of the familiar and traditional styles of assessment are based on the assumptions of the standards-based, rather than outcomes-based, model which can be a form of misalignment. The chapter also illuminates how students have been taught to use surface learning techniques because that is the type of knowledge their assessments have tended to focus on. Throughout the assessment chapters, the author maintains a pragmatic approach that attempts to balance improving assessment, without overwhelming either the student or the faculty member that does the grading with an unfinishable amount of work.

Part III of the book concentrates on the implementation of constructive alignment from the course to institutional levels. It highlights the places where change may be especially difficult - for example, constraints around switching assessments and concerns around quality assurance - and offers some strategies to mitigate these issues. Things like action research, peer review of teaching, teaching portfolios and reflection are encouraged. The final chapter reviews some specific implementation examples at the university, faculty and course level, giving a variety of views of how constructive alignment can be interpreted based on the context, and a variety of disciplines that can make use of it.

Overall, I found the book packed with information and an excellent resource for university instructors, faculty developers, and administrators. While the Gulf context is not directly addressed, it is still a helpful resource. The challenging teaching and learning environment of second language learners and varied university preparation can be addressed with many ideas presented by the authors. The style of the book regularly encourages the reader to reflect on their teaching and assessment approaches, which can be helpful to reexamine assumptions that may not have been otherwise critically analysed. Throughout each chapter, there are practical and pragmatic reflective tasks interspersed which push the 
reader to apply the ideas as they are presented with them. These tasks allow the book to be used almost like a teaching workshop. The activities throughout provide ample opportunities to consider how to apply the ideas in the reader's context. Chapters all finish with succinct summaries of the main ideas presented, and also a further reading reference list by topic should the reader wish to delve deeper.

It is easy to see why the book has made it to a fourth edition, as the ideas continue to resonate with issues faced in higher education context and help address the complex problems in today's classrooms. This is not a short read and is not filled with quick fix classroom activities or technology that the reader would pick up and use in their next class. Rather, it aims to have the reader critically analyse their overall approach to teaching and assessment at a course, department, or university-wide level. It is challenging to imagine that a reader would not have some aspect of their teaching or assessment approaches reconsidered for improvement after reading this book.

The only significant disappointment of the book is the light and outmoded treatment of e-learning. The discussion is primarily product-focused, and never unites uses of technology into the day-to-day work of teaching and assessment. Even despite the relatively recent 2011 publication date, technology is treated as an optional add-on, and the e-learning section does not integrate as strongly as it might with the concepts presented throughout the rest of the book.

While this might not be the first book to recommend to a new university instructor because it is so dense with information, anyone who has felt a level of frustration that their teaching is not quite achieving what they had hoped for will find some perspectives valuable. I would highly recommend this to university instructors as they work their way through the challenges of a changing and more demanding student population and curriculum. 